\title{
Fatigue Crack Behavior of Stainless Steel 304 by the Addition of Carbon Nanotubes
}

\author{
Rizwanulhaque Syed and Wei Jiang \\ School of Mechanical Engineering, Dalian University of Technology, Dalian, Liaoning 116024, China \\ Correspondence should be addressed to Rizwanulhaque Syed; syedrizwanulhaq@hotmail.com and Wei Jiang; jiangwei@dlut.edu.cn
}

Received 26 January 2014; Accepted 19 February 2014; Published 7 April 2014

Academic Editor: Chunyi Zhi

Copyright (C) 2014 R. Syed and W. Jiang. This is an open access article distributed under the Creative Commons Attribution License, which permits unrestricted use, distribution, and reproduction in any medium, provided the original work is properly cited.

Fatigue is the main source of almost half of whole mechanical failures. This research investigated the effect on cyclic fatigue behavior of stainless steel 304 (SS304) when including carbon nanotubes (CNTs) at the crack tip. The cyclic fatigue tests were conducted on compact tension (CT) specimens to establish the relationship between crack growth and the number of cycles $(a-N)$. It is found that the incorporation of a small amount of CNTs increased the fatigue life of the SS304/metal. Micrographs showed that the enhancement in fatigue life is caused by CNTs dense arrangement around the crack tip, entangled with each other, and finer grain size. Smooth bonding at the interface of the CNTs and SS304 grains is also observed.

\section{Introduction}

Fatigue is progressive and localized structural damage that occurs when a material is subjected to cyclic loading and is one of the primary causes for catastrophic failure in structural materials. Enhancement of fatigue life is desired for improving utility of the materials.

Researchers have studied the consequences of fractal phenomena of metal material. They described that the affected fatigue life is divided into the following three factors: [1] (i) material and structure-related factors, such as (a) type of dislocation slip, (b) grain size, (c) dislocation density and distribution, (d) texture, and (e) residual stresses; (ii) loading factors: (a) stress ratio, (b) mean stress, (c) frequency, (d) temperature, and (e) environment; and (iii) designing factors: (a) specimen shapes and dimensions (b) surface conditions, like finishing and hardening or softening treatment of the surface layer.

Cracks can be arrested and blunt by the following techniques: (a) applying compressive residual stress on the crack tip [2-6], (b) grain refinements [3, 4, 6, 7], (c) changing the shape of the crack tip $[2,8,9]$, and (d) reorientation of the crack-growth direction [2, 10, 11]. These approaches have been achieved by using various methodologies and techniques, that is, (a) laser shock processing (LSP), a coldworked process, and shot peening (SP); (b) severe plastic deformation (SPD); (c) welding and electromagnetic heat; and (d) pinhole, dimples, drilling stop holes, and inserting pins. These techniques have some application limitations such as a specimen size, arrangement of instruments, and residual stress after treatment like welding. In this work, these limitations have been considered, thereby yielding a seamless application with no defects after treatment.

Because of the outstanding mechanical and physical properties and large specific surface area of carbon nanotubes (CNTs), CNT-based composites are expected to show significantly improved mechanical performance, when compared with the neat matrix material [12]. Recently, CNTs have been used to arrest the crack propagation of polymer composites [13-21]. The crack-bridging and pullout causes the fatigue crack growth suppression in composites and has been reported as the main mechanism of crack arresting [17-21]. It has been also observed that changing the physical dimension of CNTs and improving the dispersion could enhance fatigue life significantly.

Stainless steel $304\left(\mathrm{Cr}_{18} \mathrm{Ni}_{8}\right)$ is one of the most widely used and oldest stainless steels. It was originally called 188, which stood for its chromium and nickel contents [22]. It is mainly used in the nuclear industry and in the marine 
TABLE 1: Filler multiwalled carbon nanotubes (MWCNTs) properties.

\begin{tabular}{lcccccccc}
\hline $\begin{array}{l}\text { Particle } \\
\text { size }(\mathrm{nm})\end{array}$ & Length $(\mu \mathrm{m})$ & Specific surface area $\left(\mathrm{m}^{2} / \mathrm{g}\right)$ & Content $(\%)$ & Amorphous carbon $(\%)$ & Co $(\%)$ & Mo $(\%)$ & $\mathrm{Mg}(\%)$ & Silicate $(\%)$ \\
\hline $10-30$ & $5-15$ & $>60$ & $>98$ & $<2$ & 0.08 & 0.1 & 0.12 & 0.05 \\
\hline
\end{tabular}

TABLE 2: The $\mathrm{CO}_{2}$ laser treatment parameters.

\begin{tabular}{lccccc}
\hline Laser type & Laser spot $(\mathrm{mm})$ & Power $(\mathrm{W})$ & Temperature $\left({ }^{\circ} \mathrm{C}\right)$ & Scan time $($ Sec. $)$ & $\sim 1$ \\
\hline $\mathrm{CO}_{2}$ & 2 & 1000 & $\sim 1000$ & Filler \\
\hline
\end{tabular}

environment because it is slightly higher in strength and wear resistance than the type 316. Typical applications include tanks and containers for a large variety of liquids and solids.

Ren et al. [23] reported the effect laser shock processing (LSP) on $00 \mathrm{Cr} 12$ alloy's mechanical properties at high temperatures. The results suggested that LSP has a significant effect on enhancing fatigue by applying the compressive residual stress. At high temperatures, the plasticity of alloys enhanced and formed the stable dislocations. It is relatively effective to enhance the mechanical properties. In another work by Ren et al., LSP was used to enhance the fatigue behavior of the structure [5]. They observed LSP at different laser intensities which had an obvious influence on fatigue crack initiation and the growth of the hole crack.

Zhang et al. [20] described an order of magnitude diminution in the fatigue crack growth rates for an epoxy system with the addition of a small amount of CNTs. They observed that the crack suppression was made by pullout CNTs that bridge the crack interface. This group of researchers also studied the effect of CNT dimensions on fatigue crack growth suppression in epoxy composites in another study [21]. They discovered that fatigue crack growth rates can be significantly reduced by reducing the diameter and increasing the length of the CNTs and improving the nanotube dispersion.

In this work, we enhanced the fatigue life of stainless steel 304 (SS304) by the addition of small amounts of CNTs on localized structure. To the best of our knowledge, there are no studies reporting the effect of CNTs on the fatigue life of metals (steel). Fatigue tests were conducted using compact tension (CT) specimens with and without multiwalled carbon nanotubes (MWCNTs). The fracture surfaces of the treated and untreated SS304 were examined by using scanning electron microscopy. It observed that the addition of CNTs has significant effect on fatigue crack growth of SS304.

\section{Experiment}

2.1. Materials. In this work, the SS304 is used in plate form with a chemical composition in weight of $18 \% \mathrm{Cr}, 10.5 \% \mathrm{Ni}$, $0.08 \%$ C, $1.0 \% \mathrm{Si}, 2.0 \% \mathrm{Mn}, 0.045 \%$ P, $0.03 \% \mathrm{~S}$ and balance Fe as received from Kunshan DKC Co., Ltd. Other mechanical properties of the as-received steel plate at room temperature were: ultimate tensile strength of $520 \mathrm{~N} / \mathrm{mm}^{2}$, yield strength of $205 \mathrm{~N} / \mathrm{mm}^{2}$ and $40 \%$ elongation, respectively. The chemical compositions and important parameters of as received
MWCNTs from Xuzhou Jiechuang New Material Technology Co., Ltd. are listed in Table 1.

2.2. Sample Preparation. The specimens for the CT fatigue test were prepared from an annealed sheet of SS304 in accordance with ASTM E647-12 standards. A notch was made by using a computer numerical control (CNC) cutting machine. A CNC drilling machine was used to drill two holes in the specimen. A precrack needed to be created in the specimens. A crack was made by using a Mitsubishi high performance wire EDM systems. The crack had a length of $4 \mathrm{~mm}$ and a width of $0.012 \mathrm{~mm}$. The dimensions of the specimen are shown in Figure 1.

$\mathrm{CO}_{2}$ laser was used to diffuse the MWCNTs on the substrate material's crack tip. The laser beam was focused perpendicularly on the sample surface using a planoconvex lens $(f=300 \mathrm{~mm})$ with the spot diameter of $2 \mathrm{~mm}$ and an exposure time of $\sim 1$ seconds. This configuration gives a laser power of $1000 \mathrm{~W}$ at the sample surface. The expected temperature of $1000^{\circ} \mathrm{C}$ on the sample surface was considerably less than the melting point $1399^{\circ} \mathrm{C}$ of SS304. The laser parameters are tabulated in Table 2 . The specimens were treated on both sides with the same conditions, as presented in Figure 2.

2.3. Measurement and Methods. Fatigue tests were conducted at room temperature on a servohydraulic test machine (MTS Model 810). CT specimens were prepared for fatigue test. The specimens were fatigue-tested under cyclic load and the stress ratio, defined as the ratio of minimum stress to maximum stress, was set to $R=0.1$. The shape of the loading waveform was sinusoidal and the frequency used was $20 \mathrm{~Hz}$. The testing conditions used in the experiment are presented in Table 3. The number of cycles to failure $(N)$ and crack growth $(a)$ were recorded for each specimen. Fracture surfaces of the fatigue tested samples were polished and etched then observed using scanning electron microscope (SEM). The Energy Dispersive $\mathrm{X}$-Ray Spectroscopy (EDS) defines the chemical composition after addition of the MWCNTs.

\section{Results and Discussion}

3.1. Fatigue Crack Growth. The crack propagation behavior of the MWCNTs for treated and untreated specimens at same load condition shows in Figure 3. For treated MWCNTs specimens, cracks grow slower than untreated specimens. 


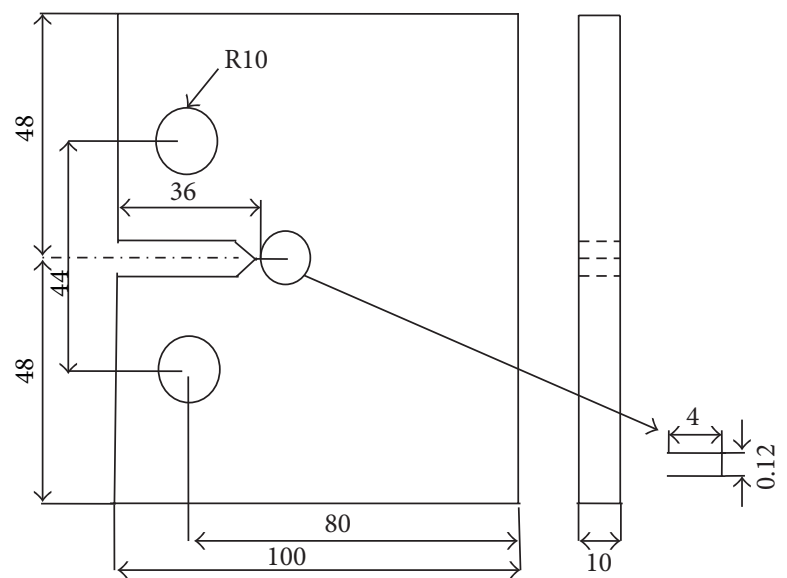

FIGURE 1: Dimensions of compact tension specimen.

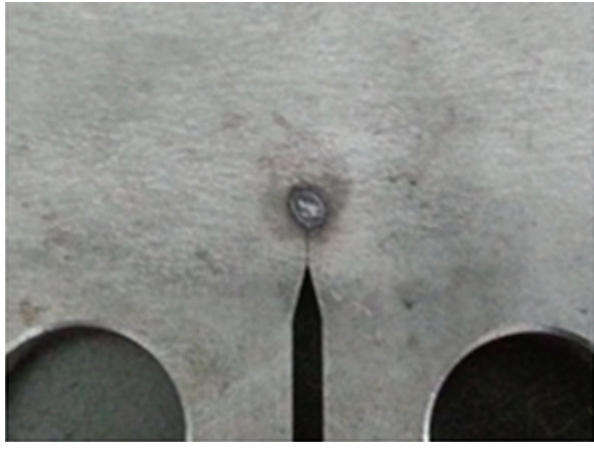

(a)

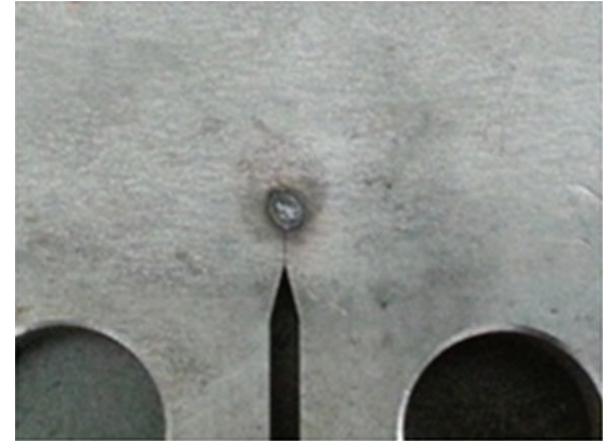

(b)

FIgURE 2: The two sides of the treated specimen: (a) upper side and (b) lower side.

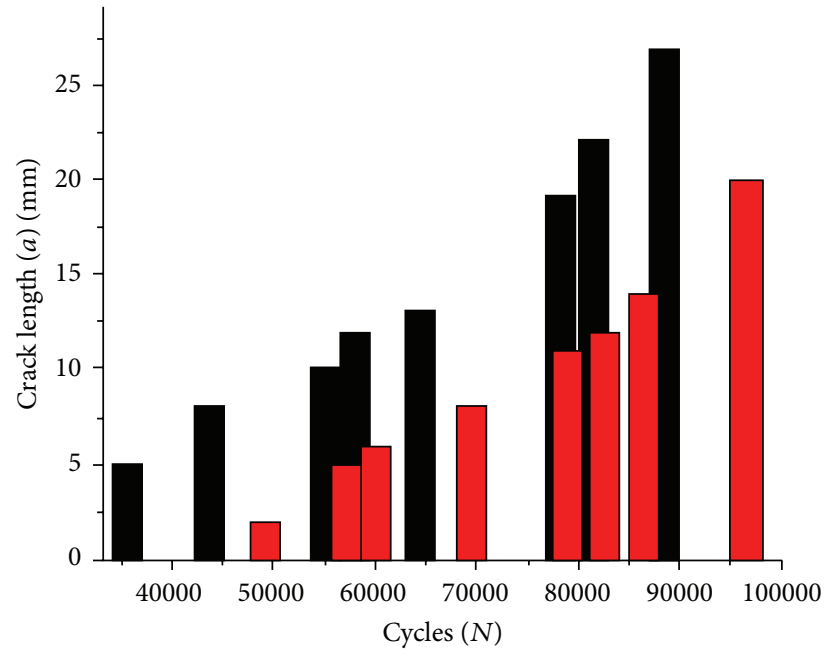

Untreated specimen

Treated specimen

FIGURE 3: The crack propagation behavior for treated and untreated specimens at the same conditions. 
TABLE 3: The testing conditions used in the experiments.

\begin{tabular}{lccccc}
\hline Max. load $(\mathrm{KN})$ & Min. load $(\mathrm{KN})$ & Target set point $(\mathrm{KN})$ & Amplitude $(\mathrm{KN})$ & Frequency $(\mathrm{Hz})$ & Tests performed \\
\hline 17 & 1.7 & 9.35 & 7.65 & 20 & Untreated CT specimen \\
Treated CT specimen
\end{tabular}

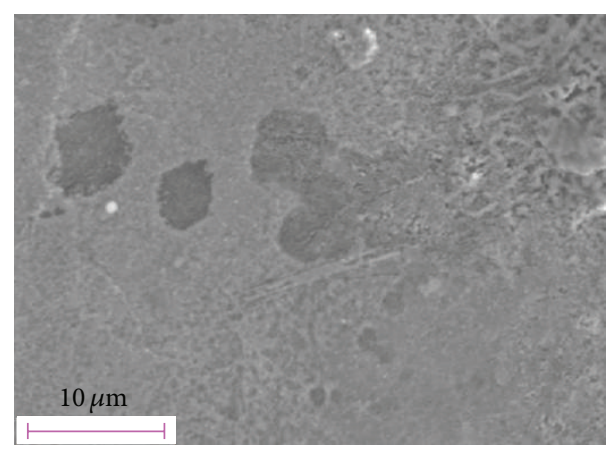

(a)

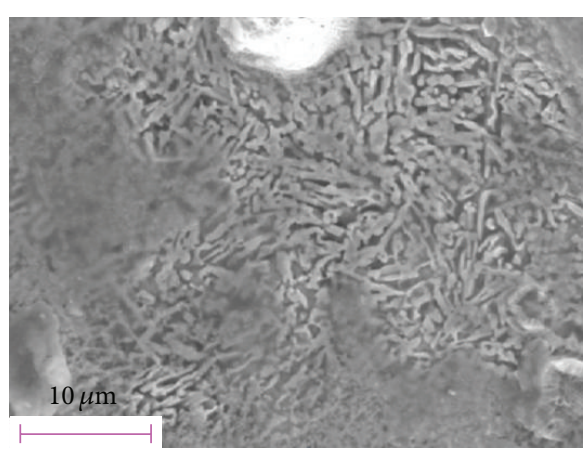

(b)

FIgURE 4: Microstructure morphology (a) before and (b) after treatment.

The small addition of MWCNTs shows a significantly larger improvement in fatigue life. The fatigue test showed the median fatigue life of the treated specimen improved $40 \%$ over the untreated. These are significant improvements in the fatigue life of SS304 and represent an opportunity to utilize SS304 in high-cycle fatigue applications by adding small fractions of CNTs. It has been reported that CNTs can suppress the failure in material [20]. The filler scale also has effects on crack propagation. The filler in nanosize may encounter crack propagation more than the filler in microsize. However, SEM characterization confirms fatigue enhancement mechanisms, as will be discussed later.

The larger effect that the addition of CNTs has on fatigue life over neat SS304 may be explained by first considering the observed failure mechanisms in specimens subjected to cyclic loading. The neat SS304 had significant and extensive damage after a few cycles at cyclic stress amplitudes. With continued cycling, cracking began to propagate rapidly. The treated CNT specimen had limited damage at same stress levels. With continued cycling, cracking propagated slowly.

The effectiveness of treated CNTs specimens at the same cyclic stress level relative to neat SS304 can be explained by the fatigue failure mechanism described above. Damage propagation occurs, with untreated SS304 at a high stress level and at a rapid rate. Under these conditions, there are no obstacles or, in this case, no CNTs in the path of the damage that could slow damage propagation. However, the damage propagation of treated SS304 at the same stress level is slower and at a widely spaced crack front. This can be slowed relatively effectively since a larger fraction of the strain energy must be dissipated in overcoming the obstacles. Thus, the addition of CNTs is more likely to be effective in improving fatigue life.

3.2. Microstructure Morphology. Figure 4 shows the SEM micrographs of the fracture surfaces of the two specimens after polishing and etching with acid. The MWCNTs containing a specimen show MWCNTs entangled with each other. It also shows random distribution of MWCNTs (see in Figure 4(b)). The entanglement of MWCNTs and high dens dispersion ensure the high strength and resist the crack growth.

The small amount of the MWCNTs was added at the SS304 crack tip of SS304 by using a laser as a heating medium. The crack tip is chilled by conduction through the metal around, after laser treatment. The metal at the crack tip is refined in the process of crystallization which creates a smooth bonding with MWCNTs. The interface of the grain boundary around the crack tip was enhanced by refining the metal structure. The alloy plasticity is enhanced at high temperatures, making dislocation slip easier [23]. It increases the interface resistance of the crack extension and work of the crack extension as well to prevent the crack propagation [24].

The addition of the MWCNTs also results in change in metal fatigue properties. The distribution of MWCNTs across the whole cross-sectional area is uniform as shown in Figure 5. The dispersions of the MWCNTs beside the crack is more than the other areas are shown by an arrow. The substrate interface shows the strong and smooth bonding of MWCNTs with the substrate. It observed that the bottom part of MWCNTs grains diffused and formed a bond. The high dispersion and fine grains of MWCNT is a corroboration to enhance the fatigue life of the component.

Figure 6 presents the high dense dispersion of the CNTs on the application surface. The MWCNTs shaped like half tubes are shown by arrows in Figure 6. The composition of the treated area was measured by EDX yielding a $51.73 \%$ $\mathrm{C}-22.03 \% \mathrm{O}-0.29 \% \mathrm{Si}-1.1 \% \mathrm{Mn}-3.05 \% \mathrm{Cr}-19.32 \% \mathrm{Fe}$ and $2.48 \% \mathrm{Ni}$. This indicates that the CNTs were oxidized and solidified in half-tube shape as shown in Figure 6(c). It can also be seen in the Figure 6 that CNTs entangled each other and made stable dislocations. The arrows point 


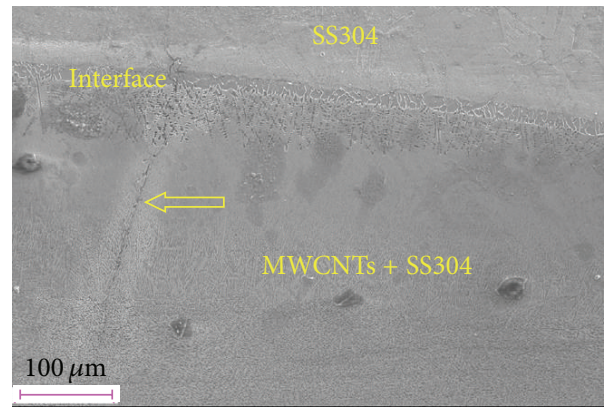

FIGURE 5: SEM image of SS304, the MWCNT's penetration and arrangement.
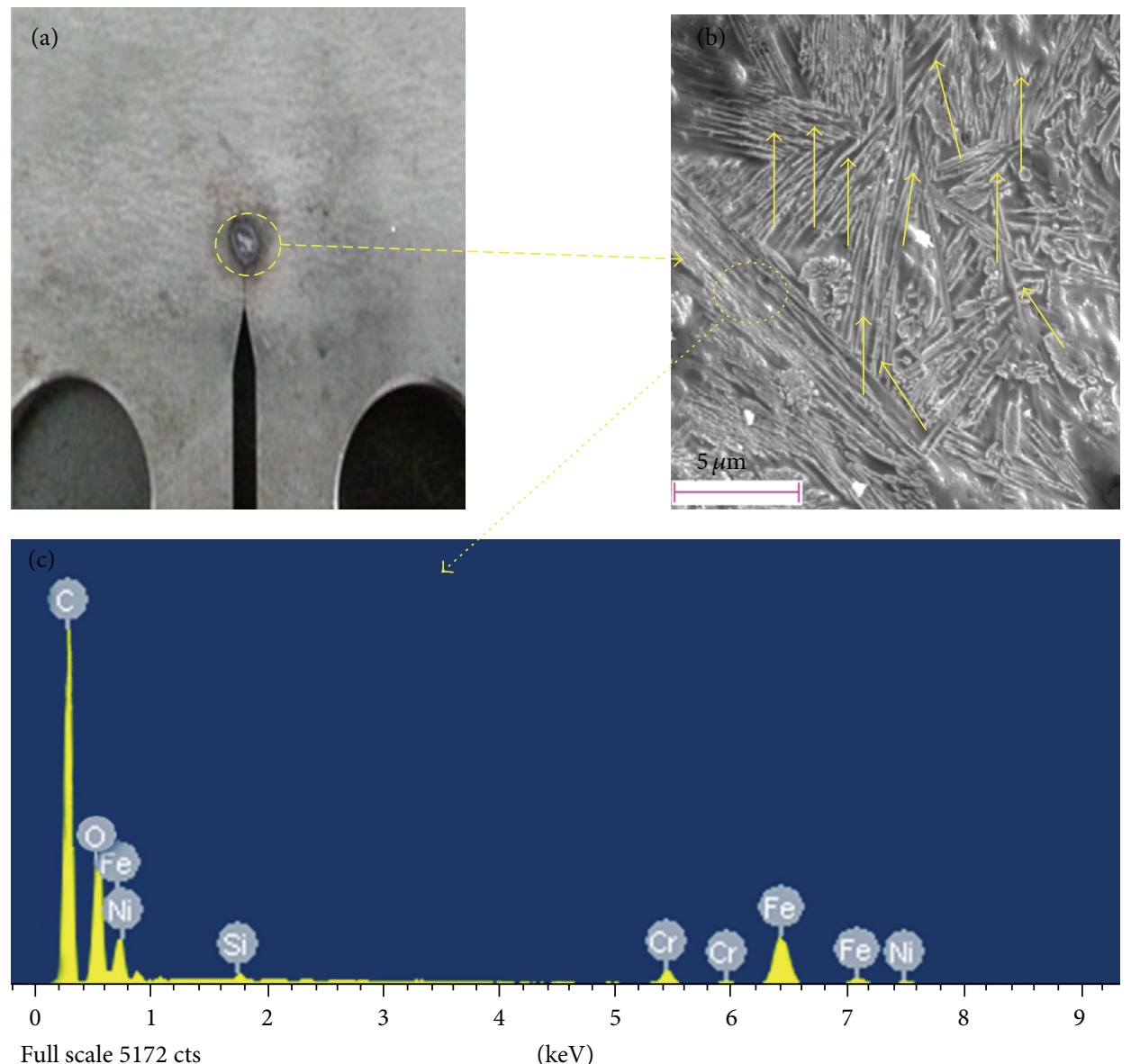

Figure 6: (a) After treatment; (b) SEM of surface of specimen containing MWCNTs: the arrows point to CNTs damage (remaining half tubes); and (c) EDX of treated area.

to the nanotubes reshaped in half-tube structures. The high dispersion of the CNTs, high dislocation density and stable dislocations, and fine grain boundaries are the main reasons that the SS304 resisted crack growth and had enhanced fatigue life $[20,21,23]$.

\section{Conclusion}

Suppression of the crack propagation in SS304 by the addition of MWCNT was investigated. It is observed that the addition of small amounts of MWCNTs significantly improves the fatigue performance of SS304. We report an increase in fatigue life of SS304 in the high cycle. Surface structures of the treated area showed that the enhancement in fatigue life is caused by the CNTs dense arrangement around the crack tip. Entanglement of MWCNTs with each other makes the dislocation stable and the grain size finer. The MWCNTs have smooth bonding at the interface. This work demonstrated the potential of CNTs in improving the fatigue life of SS304.

\section{Conflict of Interests}

The authors declare that there is no conflict of interests regarding the publication of this paper. 


\section{Acknowledgments}

The authors would like to thank the financial support of the National Natural Science Foundation of China (Grant no. 51075050) and Chinese Government Scholarship Council. They would also like to thank Professor CunShan Wang from the School of Material, Professor XingLin Guo, Professor MingFa Ren from the School of Engineering Mechanics, and Associate Professor Asif Iqbal from the School of Mechanical Engineering for help and guidance in the experiment.

\section{References}

[1] L. Joo-Sung and H. N. Tan, "A study on effect of residual stress on crack growth of aluminum plate," in Proceedings of the 1st International Forum On Strategic Technology "e-Vehicle Technology" (IFOST '06), pp. 369-373, October 2006.

[2] A. Y. Chen, D. F. Li, J. B. Zhang, F. Liu, X. R. Liu, and J. Lu, "Study of toughening mechanisms through the observations of crack propagation in nanostructured and layered metallic sheet," Materials Science and Engineering A, vol. 528, no. 29-30, pp. 8389-8395, 2011.

[3] J. Z. Lu, K. Y. Luo, F. Z. Dai et al., "Effects of multiple laser shock processing (LSP) impacts on mechanical properties and wear behaviors of AISI 8620 steel," Materials Science and Engineering A, vol. 536, pp. 57-63, 2012.

[4] J. Z. Lu, K. Y. Luo, Y. K. Zhang et al., "Grain refinement mechanism of multiple laser shock processing impacts on ANSI 304 stainless steel," Acta Materialia, vol. 58, no. 16, pp. 53545362, 2010.

[5] X. D. Ren, Q. B. Zhan, H. M. Yang et al., "The effects of residual stress on fatigue behavior and crack propagation from laser shock processing-worked hole," Materials \& Design, vol. 44, pp. 149-154, 2013.

[6] I. B. Roman, A. S. Banea, and M. H. ȚIerean, "A review on mechanical properties of metallic materials after laser shock processing," Bulletin of the Transilvania University of Brasov, Series I: Engineering Sciences, vol. 4, no. 2, pp. 81-86, 2011.

[7] L. Ladani and S. Nelson, "Transition of crack propagation path under varied levels of load in bimodal grain size Al-Mg alloy," Journal of Engineering Materials and Technology, vol. 133, no. 4, Article ID 041017, 2011.

[8] Y. Fu, G. Zheng, L. Zheng, J. Zhang, and H. Liu, "Analysis on residual stress after crack arrested by using electromagnetic heating," Journal of Plasticity Engineering, vol. 19, no. 1, pp. 103106, 2012.

[9] H.-C. Zhang, J. Yu, and A. Iqbal, "Application of electromagnetic heat effect on crack arrest in remanufacturing blank," in Re-engIneerIng ManufacturIng for SustaInability, A. Y. C. Nee, B. Song, and S. K. Ong, Eds., pp. 627-632, Springer, Singapore, 2013.

[10] C. Makabe, A. Murdani, K. Kuniyoshi, Y. Irei, and A. Saimoto, "Crack-growth arrest by redirecting crack growth by drilling stop holes and inserting pins into them," Engineering Failure Analysis, vol. 16, no. 1, pp. 475-483, 2009.

[11] A. Murdani, C. Makabe, A. Saimoto, and R. Kondou, "A crackgrowth arresting technique in aluminum alloy," Engineering Failure Analysis, vol. 15, no. 4, pp. 302-310, 2008.

[12] M. R. Loos, L. A. F. Coelho, S. H. Pezzin, and S. C. Amico, "Effect of carbon nanotubes addition on the mechanical and thermal properties of epoxy matrices," Materials Research, vol. 11, no. 3, pp. 347-352, 2008.
[13] L. Böger, J. Sumfleth, H. Hedemann, and K. Schulte, "Improvement of fatigue life by incorporation of nanoparticles in glass fibre reinforced epoxy," Composites Part A: Applied Science and Manufacturing, vol. 41, no. 10, pp. 1419-1424, 2010.

[14] C. S. Grimmer and C. K. H. Dharan, "High-cycle fatigue of hybrid carbon nanotube/glass fiber/polymer composites," Journal of Materials Science, vol. 43, no. 13, pp. 4487-4492, 2008.

[15] Y.-M. Jen and Y.-H. Yang, "A study of two-stage cumulative fatigue behavior for CNT/epoxy composites," Procedia Engineering, vol. 2, no. 1, pp. 2111-2120, 2010.

[16] M. R. Loos and K. Schulte, "Is it worth the effort to reinforce polymers with carbon nanotubes?" Macromolecular Theory and Simulations, vol. 20, no. 5, pp. 350-362, 2011.

[17] Y. Ren, Y. Q. Fu, K. Liao, F. Li, and H. M. Cheng, "Fatigue failure mechanisms of single-walled carbon nanotube ropes embedded in epoxy," Applied Physics Letters, vol. 84, no. 15, pp. 2811-2813, 2004.

[18] Y. Ren, F. Li, H. Cheng, and K. Liao, “Tension-tension fatigue behavior of unidirectional single-walled carbon nanotube reinforced epoxy composite," Carbon, vol. 41, no. 11, pp. 2177-2179, 2003.

[19] N. Yu, Z. H. Zhang, and S. Y. He, "Fracture toughness and fatigue life of MWCNT/epoxy composites," Materials Science and Engineering A, vol. 494, no. 1-2, pp. 380-384, 2008.

[20] W. Zhang, R. C. Picu, and N. Koratkar, "Suppression of fatigue crack growth in carbon nanotube composites," Applied Physics Letters, vol. 91, no. 19, Article ID 193109, pp. 1-3, 2007.

[21] W. Zhang, R. C. Picu, and N. Koratkar, "The effect of carbon nanotube dimensions and dispersion on the fatigue behavior of epoxy nanocomposites," Nanotechnology, vol. 19, no. 28, Article ID 285709, pp. 1-5, 2008.

[22] http://www.outokumpu.com/SiteCollectionDocuments/ Datasheet-304-304l-imperial-hpsa-outokumpu-en-americas .pdf.

[23] X. D. Ren, T. Zhang, Y. K. Zhang et al., "Mechanical properties and residual stresses changing on 00Cr12 alloy by nanoseconds laser shock processing at high temperatures," Materials Science and Engineering A, vol. 528, no. 4-5, pp. 1949-1953, 2011.

[24] C. J. Lai, "Research and analysis on pulse discharge crack arrest in welding junction," Mechanical Engineering, 2006. 

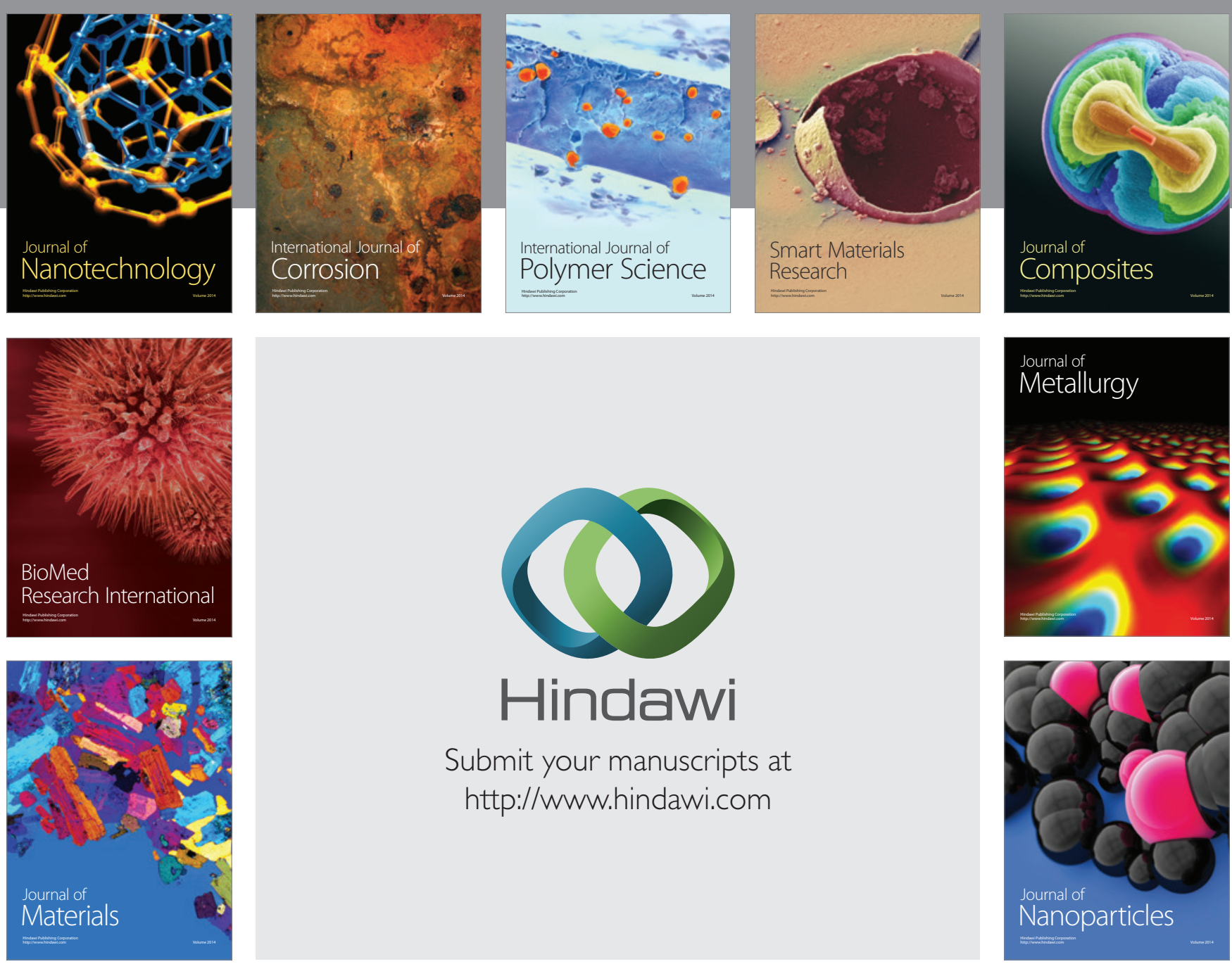

Submit your manuscripts at http://www.hindawi.com
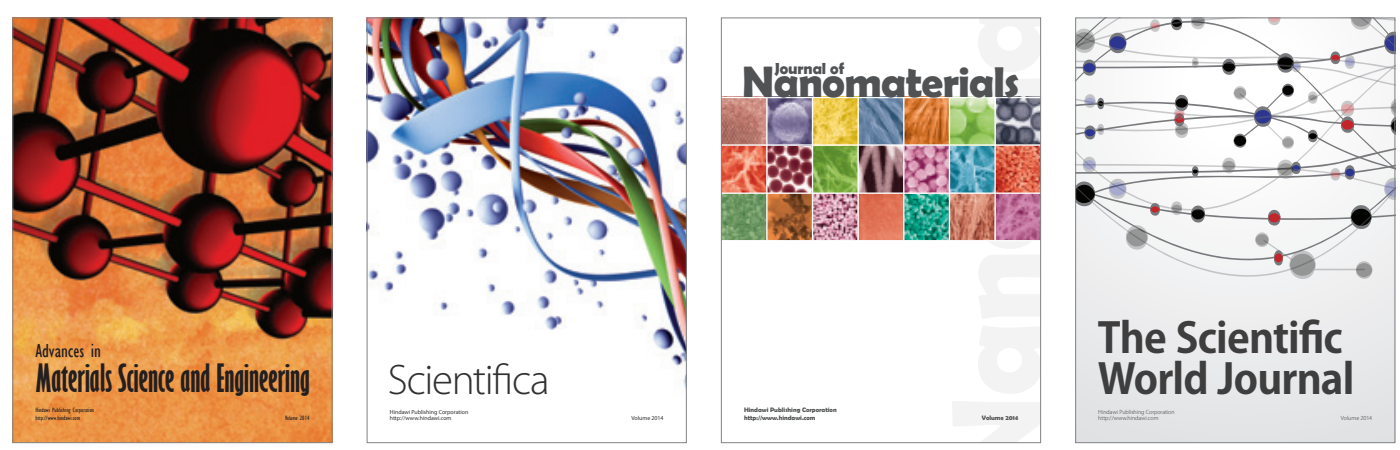

\section{The Scientific World Journal}
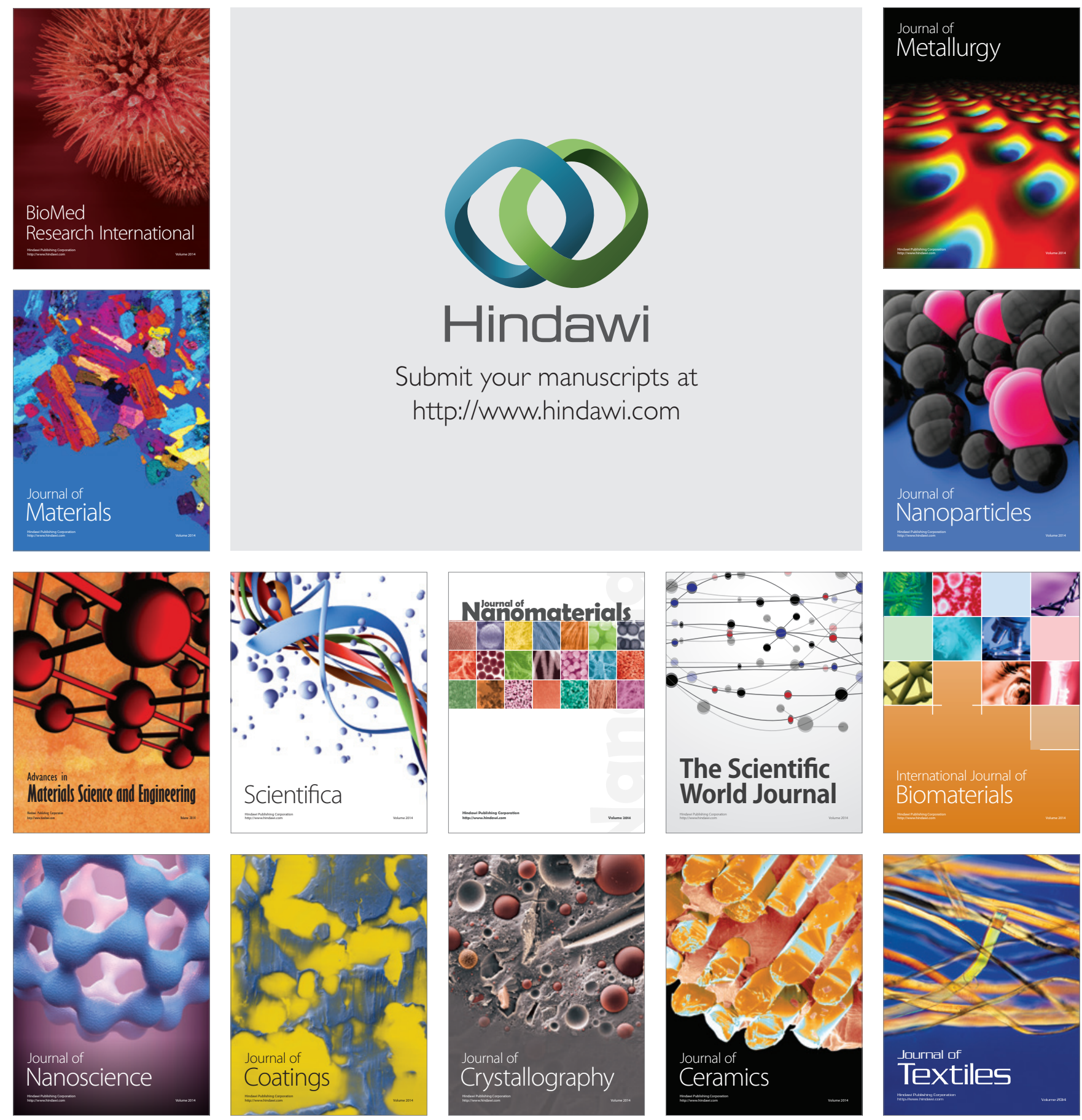